\title{
Construction of Xi'an TCM (Traditional Chinese Medicine) International Exchange Platform under "the Belt and Road Initiative"
}

\author{
Aixiang Huo \\ Xi'an Peihua University, Xi'an Shaanxi, 710125, China
}

Keywords: traditional Chinese medicine; the Belt and Road Initiative; cultural

\begin{abstract}
Since ancient time, TCM as the important contents of the exchanges and cooperation between countries along the ancient Silk Road, has taken root in countries along the route along with trading activities and has become health resources shared and co-built by people along the route in different forms. In the 7-10th century AD, TCM widespread throughout the world with the prosperity of the Tang and Song dynasties, and became the main treatment theory and method in many places. In the 19th century, the rapid development of Western medicine brought about a certain degree of impact on traditional Chinese medicine. However, due to the increasingly prominent drug resistance, toxic and side effects of chemical medicine, traditional medicine receives popularity among the public again due to its specifically safe, economic and humane healthcare model. Particularly since the 1990s, its influence in other countries has been further expanded. So far, TCM has been transmitted to more than 183 countries and regions in the world.
\end{abstract}

\section{Introduction}

In March 2015, the Chinese government issued the "Vision and Action for Promoting the Joint Construction of the Silk Road Economic Belt and the 21st Century Maritime Silk Road," which marked the "One Belt and One Road Initiative" to enter the all-round construction phase, and marked the arrival of a new era of globalization characterized with China's "Going Global" strategy.

\section{Difficulties of TCM Going Global}

\subsection{Developmental disequilibrium and differential acceptability}

Development of traditional Chinese medicine in countries along the "One Belt and One Road" is imbalanced with a big difference in the degree of national legislation and public recognition. In general, TCM has received high recognition from the government and the public in Southeast Asia, and there is a general lack of legislation and management of traditional Chinese medicine in Central Asia, West Asia, and Africa. However, in Europe, management of traditional Chinese medicine is mostly under restrictive laws and regulations for the excuse of safety, which affects the development of TCM international cooperation.

Overseas countries with clear legislation on TCM include Singapore and Thailand. North Korea, South Korea, and Vietnam traditional medicine mainly originating from Chinese traditional medicine has been included in the national legal health care system [3]. TCM is still regarded as an "alternative and complementary therapy" in Western countries. Most countries have insufficient understanding of the overall theory of TCM syndrome differentiation and treatment. Therefore, most legislations tend to treat acupuncture and moxibustion independently with TCM. Chinese medicine practitioners can obtain the title of "doctor" in few countries that recognize officially. The United Kingdom was the first country in Europe to enact legislation on complementary and alternative medicine. However, in 2011, Britain suddenly cancelled the legislation and left it in a stagnant state. Acupuncture is only allowed for medical activities in Italy. Other European countries such as the Czech Republic, Sweden, etc. have no legislation for Chinese medicine, nor relevant regulatory agencies. However, the efficacy and safety of TCM have been verified through thousands of years of practice, integrated with the 
promotion of the concept "back to nature", which has improved the popularity and recognition of traditional Chinese medicine in the world.

The ancient traditional Chinese medicine is by no means backward, which integrated thousands of years of wisdom from ancient Chinese doctors and proposed a holistic viewpoint that human beings and nature are united in a unified and harmonious relationship related to the health of the people. And TCM has plays an important role. China as the origin of TCM culture should promote the western countries to face up to Oriental medicine, accept TCM culture, and be good at using various diagnosis and treatment methods to provide health service for people.

\subsection{The standardization of Chinese medicine has not been established}

TCM is a product of thousands of years of medical practice in the Chinese nation, the crystallization of people's experience in repeated application, which is very different from the laboratory verification of Western medicine which is experimentally verified by animals and then introduced to the market. Therefore, the effectiveness and safety of TCM is questioned in the clinical application.

\subsection{Lack of depth and breadth of international cooperation and the existence of trade barriers}

International cooperation of TCM should be further strengthened in the construction of overseas centers, the cultivation of internationalized talents, and the cooperation in scientific research. Many countries use laws and regulations to set up trade barriers on the basis of technology in the process of legislative recognition and regulation of TCM, which created new difficulties and barriers for TCM admittance.

\subsection{Inaccurate translation of traditional Chinese medicine has also caused negative effects on its communication and exchange}

It is a widespread phenomenon that Foreigners do not understand Chinese but professional TCM doctors know little about foreign languages, and translators of Chinese medicine do not understand TCM. Translation of TCM has become a major obstacle for TCM overseas publicity.

\section{Important Significance of Building TCM International Exchange Platform}

\subsection{Adapt to the strategy of culture power strategy}

In October 2011, the Sixth Plenary Session of the 17th CPC Central Committee deliberated and adopted the "Decision on Deepening Cultural System Reforms to Promote Major Development and Prosperity of Socialist Culture," and established a "culturally strong country" development strategy. Traditional Chinese medicine is not only a life science, but also the essence of traditional Chinese culture, as well as a medicine that combines the attributes of humanities and natural sciences. The facts have fully proved that using Chinese medicine as an entry point is an effective and feasible method for spreading Chinese culture. At present, Chinese medicine has spread to 183 countries and regions in the world and is gradually gaining recognition and acceptance from the international community with its unique advantages.

\subsection{Adapt to TCM overseas development strategy}

For the past few years, the Party Central Committee and the State Council attached great importance to improving the status and role of Chinese medicine in government communication, and overseas development of TCM has obtained hard-won historical opportunity. As a unique diplomatic means, Chinese medicine has effectively cooperated with our country's diplomatic work and enhanced our country's international influence.

\subsection{Adapt to TCM planning outline requirements}

In April 2009, the State Council issued to implement the "Several Opinions of the State Council on Supporting and Promoting the Development of Traditional Chinese Medicine", clearly indicating the 
necessity to "actively participate in traditional medicine activities carried out by relevant international organizations and further develop TCM exchanges and cooperation with foreign governments, companies, medical institutions, research institutes and institutions of higher education, improve relevant policies, and actively expand trade in Chinese medicine services, strengthen the promotion of TCM knowledge and culture, and promote international communication. In February 2016, the State Council issued the "Outline of the Strategic Plan for the Development of Traditional Chinese Medicine (2016-2030)", clearly stating to support Chinese medicine institutions to participate in the construction of the "Belt and Road Initiative" and to explores the construction of a number of overseas centers for traditional Chinese medicine.

Building an international exchange platform for TCM integrating resources and internal and external functions, connecting government, enterprises, academia, and foreign needs, will play an important role in the future of TCM foreign cooperation and exchange. Therefore, it deserves our deep consideration about how to build an internationalized exchange platform for TCM and to make it radiate and promote the development of the entire Chinese medicine overseas exchange and cooperation industry.

\section{Several Suggestions of Building Xi'an TCM International Exchange Platform}

As the departure port of the ancient Silk Road and the bridgehead of "One Belt and One Road", integrating the city's concentrated advantages in TCM resources, Chinese medicine industry, education, science and technology, and culture, to build Xi'an's TCM international exchange platform will have great significance.

This article believes that international exchange platform for traditional Chinese medicine should connect different needing parties including Chinese and foreign governments, companies, academia and have functions of resource collection through both internal and external. To be specific, the platform's functions must be embodied as follows: the national image display platform, education platform, academic exchange platform, industry cooperation platform, and cultural communication and promotion platform.

\subsection{Give full play of the educational functions of TCM international exchange platform and focus on cultivating TCM international talents}

\subsubsection{Vigorously launch overseas TCM school-running}

TCM internationalized exchange platform should give full play to its educational functions and actively carry out TCM overseas education advocated by the Chinese government. Since the 1970s, acupuncture and moxibustion spread throughout the world has become an important part of supplemental medicine and medical care in countries all over the world. In recent years, due to its smaller formula, more common drugs, standardized medications, clearer indications and adaptation to Westerners' thinking modes, the traditional classical prescription has gradually become popular in the world.

To cultivate clinical talents of overseas TCM practitioners, we must constantly explore innovative teaching models and educational concepts by starting from the ancient Chinese history and learning Chinese literary classics, and adding courses such as Ancient Chinese, Traditional Chinese Medicine Theory and Clinics, and Chinese Classical Philosophy to make up for students' weaknesses in the cultural basis of TCM learning and to enable students to understand the source of the culture as the true "missionary" of TCM.

\subsubsection{Strengthen the construction of teaching staff and compile high-level TCM bilingual teaching materials}

For TCM international communication, transmission of TCM classical theory to the world is one of the important bridges. Therefore, the accurate foreign language translation of classical Chinese medicine works and the compilation of high-level Bilingual teaching materials are undoubtedly effective means to spread the culture of Chinese medicine on an international scale. 
A lot of TCM books are written in ancient Chinese with unique theories. Many terms can only found in traditional Chinese medicine, which makes it difficult to express in foreign languages accurately. This requires the bilingual teaching faculty to have a very high level of translation, familiar with the teaching of foreign languages, and to understand the theory and clinical practice of TCM, and the meanings. Only in this way can they restore the true meaning of classical Chinese classics.

\subsubsection{Enlarge the scale of TCM international talent exchange}

Domestic and foreign colleges and universities can establish TCM exchange student program through TCM exchange platform, and actively expand the channels for international personnel exchange of Chinese medicine, thus providing a good development platform for international talents of Chinese medicine. TCM exchange platform can connect domestic universities of Chinese medicine with famous universities abroad. Both parties share advanced educational concepts and superior educational resources to achieve resource integration and learn from each other. They can send students and scholars to exchange and learn TCM and make common progress. This can help spread TCM culture to the world as an important window for the TCM internationalization, and can also integrate the philosophical viewpoints of traditional Chinese medicine and the thinking of traditional Chinese medicine into the key contents of overseas students' training, so as to enable TCM into a carrier of multi-culture, and promote TCM to the world.

\subsubsection{Strengthen the coordinated development of Confucius Institutes in the region}

China has established more than 300 "Confucius Institutes" overseas with outstanding achievements in promoting Chinese language. It has become a platform for displaying and disseminating excellent traditional Chinese culture. At present, Western society has gradually accepted Chinese traditional culture. To create a new model for overseas dissemination of TCM, it is necessary to make full use of this achievement. Contents of TCM can be appropriately integrated in the teaching of the Confucius Institute, so as to enrich teaching contents "Confucius Institute" and promote the transmission of TCM culture and other excellent traditional culture. By doing so, it can penetrate deep into the community and people's daily life, achieve real-time exchanges and feedbacks, enhance people's understanding of the Chinese language and TCM culture in countries along the Belt and Road. Meanwhile, it can have subtle influence on the local culture unconsciously.

\subsection{National image publicity and display platform}

Include the construction of TCM national exchange platform into the national development strategy and lead the TCM to a level of external communication. It is of great important practical significance to promote the channels for international standardization of TCM construction, enhance the international recognition and influence of TCM, standardize and promote the international development of TCM, and enable China to grasp the dominance of international standardization of TCM. China should make full advantages of the ISO/TC249 platform and give full play to its role as a great TCM power.

\subsection{Academic exchange platform}

Academic conferences and forums can be held on TCM international exchange platform by virtue of the World Federation of Chinese Medicine Societies to regularly to attract international experts and scholars to pay attention to the development of Chinese medicine and Xi'an City, publish high-level academic papers, and expand the international influence of TCM.

\subsection{Industry cooperation platform}

TCM exchange platform can integrate domestic Chinese medicine companies, hospitals, and foreign pharmaceutical companies and hospitals, and conduct all-round cooperation.

TCM international exchange and cooperation in international scientific research has revealed the academic essence and scientific connotation of Chinese traditional medicine, which can help to gain 
understanding and recognition from the medical and scientific communities around the world. "The National TCM Medium- and Long-term Plan for External Cooperation and Exchange (2011 - 2020)" clearly states: "Support qualified TCM institutions of higher learning to establish high-level scientific and technological cooperation with international scientific research institutions, well-known enterprises, and prestigious universities, and jointly conduct research in key areas such as basic theories of Chinese medicine, clinical medicine, and TCM products with international advanced modern technologies and methods."

\subsection{Cultural communication platform}

Connect domestic TCM technicians and foreign citizens, establish network publicizing platform, and display mature and characteristic TCM technologies and products.

There exist differences between Chinese and Western cultures. Relevant publicity is necessary in the local area by virtue of the power of the media to attract foreigners to promote the international spread of TCM culture. CCTV has launched 24 hours of English channels in the United States. Xinhua News Agency has set up hundreds of branches in the world and China Daily has been published in various regions around the world. Effective use of media propaganda can play an irreplaceable role in enhancing TCM cultural generalization ability.

As the departure port of the ancient Silk Road and the bridgehead of "One Belt and One Road", Xi'an integrates the city's concentrated advantages in TCM resources, Chinese medicine industry, education, science and technology, and culture, to build Xi'an's TCM international exchange platform, and to carry out cooperative construction of TCM overseas centers, medical services, scientific research cooperation and personnel training, academic exchanges, and national image publicity, continue to expand the depth and breadth of the exchange of TCM in Xi'an, and enhance the international level and influence of TCM cooperation and exchange. This can promote Xi'an's overall strength, influence on science and technology, innovation and vitality, and humanistic charm to a new level.

\section{Acknowledgement}

This research was financially supported by the 2018 Xi'an Social Science Plan Funding Project: Studies on construction of Xi'an TCM internationalization exchange platform under "the Belt and Road Initiative" (Project No.: 18z65).

\section{References}

[1] Liu Weidong. "Scientific connotation Of One Belt and One Road strategy and scientific problems, Progress in geographical science, 2015, 34(5):538-544.

[2] Liu Tonghua, Xiao Shiying. Domestic and overseas TCM market analysis, Chinese pharmaceutical science and technology publishing house, 2010:86-87.

[3] Zuo Yanfu. Development status and prospects of TCM in the world, Jiangsu traditional Chinese medicine, 2005,26(5):1-6.

[4] Xu Zhongwei. Discussion on TCM legislation comparison in western countries, Legal System and Society, 2007,3(5):366-367.

[5] TCM international office, Department of International Cooperation, MOST. Overview of American complementary and alternative medicine, Asia-Pacific Traditional Medicine, 2006,2(5):28-38.

[6] Sun Yinping. Explroation of TCM international cooerpation exchange platform under the background of One Belt and One Road, China Medical Herald,2017(8):84-88.

[7] Jiang Jibiao. Studies on overseas TCM center development strategy, WIMCO, 2016 ( 11):567-569 